\title{
Fatigue of Reinforcing Steel Bars Subjected to Natural Corrosion
}

\author{
Shibin $\mathrm{Li}^{1,2, *}$, Weiping Zhang ${ }^{2}$, Xianglin $\mathrm{Gu}^{2}$ and Cimian $\mathrm{Zhu}^{2}$ \\ ${ }^{I}$ School of Civil Engineering, Shandong Jianzhu University, Jinan 250101, China \\ ${ }^{2}$ Department of Building Engineering, Tongji University, Shanghai 200092, China
}

\begin{abstract}
Under badly environmental conditions as well as complex loads, corrosion of embedded reinforcing steel bars in concrete is common for reinforced concrete (RC) structures. Fatigue of corrosion reinforcing steel bars is a key problem for old RC bridges. To assess the residual fatigue life of aged existing RC bridges, the most new study information on fatigue of natural corrosion reinforcement is analyzed, and axial tensile fatigue tests are conducted on fifteen naturally carbonation-induced corrosion steel bars. The fatigue test results indicate that the existence of corrosion pits reduces the fatigue life of steel bars significantly under the same fatigue stress; with the development of corrosion, the fatigue life of steel bars decays according to negative power exponent law approximately and the attenuation rate increases with stress level augment. For the complexity of fatigue and corrosion, further pertinent conclusions remain to be confirmed.
\end{abstract}

Keywords: Fatigue, corrosion, reinforcing steel bar, experiment, bridge.

\section{INTRODUCTION}

Reinforced concrete structures are widely applied in civil engineering for their many merits, such as rich materials, saving steel, good fireproof and durability as well as integrity. A good-quality concrete provides a highly alkaline environment that forms a passive film on reinforcing steel bar surface, preventing the reinforcing steel bar from corroding. However, under a chloride attack or concrete carbonization, this passive film is disrupted and the steel bar begins to corrode. Corrosion of embedded steel bars was a major problem for RC structures for it may affect their residual capacity and life through four aspects, including loss of concrete section as a result of longitudinal cracking and spalling, loss of reinforcement section, change of reinforcement mechanical properties (especially fatigue), and a reduction in bond between reinforcement and concrete. Many RC structures had to be repaired or strengthened for reinforcing steel bar corrosion. It was reported that about 100 billion dollars were used to repair RC structures all over the world in 2005[1]. To some extent, the durability of concrete structure is reinforcement corrosion. Nowadays, much work has been done on the static performance of corrosion reinforcement [2]. But the research on fatigue of corrosion reinforcement is few [3].

Highway bridges, railroad bridges, and crane girders are continuously subjected to alternate loads that may cause fatigue fracture of reinforcing steel bars. When the RC structure under repeated loads is corroded, its service life can be significantly reduced for the brittle fracture of reinforcing steel bars. In China, many RC bridges along highroad or

*Address correspondence to this author at the School of Civil Engineering, Shandong Jianzhu University, Jinan 250101, China;

Tel: +86-531-86367234-101; Fax: +86-531-86993042;

E-mail: 1sbtj@163.com, 1sbtj_2007@sdjzu.edu.cn railway worked about twenty years, and deteriorated seriously for salt damage, frost and thaw condition, concrete carbonization and the increase of over-freight vehicles frequency. The effect of reinforcement corrosion on fatigue strength was therefore a matter of concern to those charged with ensuring safe operation of RC structures suffered cyclic loads. It was essential that responsible engineers have at their disposal the means to verify that the affected structures retain an acceptable margin of safety.

\section{CURRENT STATUS ON FATIGUE OF CORRO- SION REINFORCEMENT}

Essentially, fatigue of corrosion reinforcement is a key problem for corroded RC bridges. But the interrelated research was few. It was mainly because the fatigue of corroded steel bars was very complex. There was little study on the fatigue of natural corrosion reinforcement $[4,5]$.

In the literature [4], axial tension fatigue tests were conducted on fourteen natural corrosion plane steel bars with an original diameter of $19 \mathrm{~mm}$, which were made from some old RC beams of a 60-year railway bridge. The tests were controlled by load with a loading frequency about $5 \mathrm{~Hz}$. The fatigue test conditions and results are listed in Table. 1. The test datum was useless if it ruptured at clamp inside, or did not rupture. Based on the 10 effective data, the fatigue $S-N$ curve with a $95 \%$ guarantee rate of the natural corrosion plane reinforcement can be described as follows: $\lg N=$ 17.5285-5.2245 $\lg S$. In which, $N$ is fatigue life; $S$ is stress range. The correlation coefficient $(R)$ equals to negative 0.8884 , and the standard deviation is about 0.2048 . In the literature [6], the fatigue $S-N$ curve with a $95 \%$ guarantee rate of the uncorroded plane steel bars was given as follows: $\lg N=44.4580-16.3614 \lg S$. In which, the correlation coefficient $(R)$ equals to negative 0.983 , and the standard deviation is about 0.375 . The yield strength of the plane steel 
bar is about $257 \mathrm{MPa}$. The diameter of the reinforcement is $20 \mathrm{~mm}$. The loading stress ratio is from 0.047 to 0.057 with frequency about $8.33 \mathrm{~Hz}$. Eighteen specimens were tested, but ten effective data were found. Comparative analysis results between uncorroded and naturally corroded plane reinforcement were listed in the Table 2.

It was obvious that fatigue strengths of steel bars under different cycle numbers are reduced greatly due to stress concentration phenomenon caused by pits under moderate corrosion as well as loading history, especially for higher control number. With the control number increasing from $10^{6}$ to $10^{7}$, the fatigue strength drops from $28.2 \%$ to $46.8 \%$. In average, the fatigue strength of natural corrosion plane reinforcement with a mass loss of $4.60 \%$ drops $37.80 \%$.

In the literature [5], regression equation of the fatigue curve was established for corroded steel bars on the basis of taking into account the effect of reinforcement corrosion on the fatigue properties. Then, suggested values of the allowable stress ranges corresponding to different target fatigue lives under the specified ensuring probability were proposed for corroded steel bars. Through the comparison analysis of fatigue rupture section of corroded steel bar by scanning electron microscope, degenerate rule of fatigue properties of corroded steel bar was explored. The literature emphasized test study, some good conclusions were drawn. In the literature [7], the fatigue $S-N$ curves of accelerated corrosion steel bars in concrete slabs were listed for minor, medium and severe corrosion steel bars, in which the influence of cross section and stress change was considered synthetically. The condition agreed with the same loads, but steel bars were corroded. The accelerated corrosion instance was different from natural corrosion conditions. In the literatures $[8,9]$, the fatigue of steel bar subjected to accelerated corrosion was also studied, in which the influence of cross section and stress change were considered solely. In the literatures $[10,11]$, the low cycle fatigue behaviors of corroded reinforcing steel bars S400 and S500s were studied respectively. The loading condition corresponded earthquake loads. But the reinforcement types were different from those made in China. Based on the state of the art, fatigue of steel bar subjected to natural corrosion was studied in the paper.

\section{EXPERIMENTAL RESEARCH}

Corrosion of reinforcing steel bars can be divided into four conditions: natural corrosion in existing RC members, exposed corrosion in atmosphere environment, accelerated corrosion in RC members, and mechanical simulation. The

Table 1. Fatigue Test Conditions and Results of the Plane Specimens

\begin{tabular}{|c|c|c|c|c|c|c|}
\hline $\begin{array}{l}\text { Diameter } \\
\text { (cm) }\end{array}$ & $\begin{array}{c}\text { Mass } \\
\operatorname{Loss}(\%)\end{array}$ & $\begin{array}{c}\text { Upper Limit } \\
\operatorname{Load}(k N)\end{array}$ & $\begin{array}{c}\text { Lower Limit } \\
\operatorname{Load}(k N)\end{array}$ & $\begin{array}{c}\text { Stress } \\
\text { Range(MPa) }\end{array}$ & $\begin{array}{c}\text { Failure } \\
\text { Times }\left(10^{4}\right)\end{array}$ & $\begin{array}{l}\text { Fracture } \\
\text { Location }\end{array}$ \\
\hline 1.842 & 6.01 & 90 & 10 & 300.2 & 16.35 & clamp outside \\
\hline 1.863 & 3.86 & 85 & 10 & 275.1 & 16.09 & clamp outside \\
\hline 1.866 & 3.55 & 80 & 10 & 256.0 & 11.92 & clamp inside \\
\hline 1.837 & 6.52 & 75 & 10 & 245.2 & 36.10 & clamp outside \\
\hline 1.840 & 6.22 & 70 & 10 & 225.6 & 42.13 & clamp outside \\
\hline 1.839 & 6.32 & 65 & 10 & 207.1 & 58.26 & clamp outside \\
\hline 1.887 & 1.36 & 60 & 10 & 178.9 & 183.78 & clamp outside \\
\hline 1.858 & 4.37 & 80 & 10 & 258.3 & 9.72 & clamp outside \\
\hline 1.854 & 4.78 & 85 & 10 & 277.8 & 18.56 & clamp inside \\
\hline 1.855 & 4.68 & 82.5 & 10 & 268.3 & 7.77 & clamp outside \\
\hline 1.854 & 4.78 & 75 & 10 & 240.8 & 20.92 & clamp outside \\
\hline 1.858 & 4.37 & 62.5 & 10 & 193.6 & 255 & no fracture \\
\hline 1.861 & 4.06 & 62.5 & 10 & 193.0 & 64.86 & clamp outside \\
\hline 1.866 & 3.55 & 60 & 10 & 183.0 & 50.40 & clamp inside \\
\hline
\end{tabular}

Table 2. Comparative Analysis on Fatigue of Plane Reinforcement

\begin{tabular}{|c|c|c|c|c|c|c|}
\hline Condition & $\begin{array}{c}\text { Fatigue } S \text { - } N \text { curve } \\
(95 \% \text { guarantee rate })\end{array}$ & $\begin{array}{c}10^{6} \\
S(\mathrm{MPa})\end{array}$ & $\begin{array}{c}2 \times 10^{6} \\
S(\mathrm{MPa})\end{array}$ & $\begin{array}{c}3 \times 10^{6} \\
S(\mathrm{MPa})\end{array}$ & $\begin{array}{c}5 \times 10^{6} \\
S(\mathrm{MPa})\end{array}$ & $\begin{array}{l}10 \times 10^{6} \\
S(\mathrm{MPa})\end{array}$ \\
\hline Uncorroded & $\lg N=44.4580-16.3614 \lg S$ & 224.15 & 214.85 & 209.59 & 203.15 & 194.72 \\
\hline Corroded & $\lg N=17.5285-5.2245 \lg S$ & 160.92 & 140.93 & 130.41 & 118.26 & 103.57 \\
\hline
\end{tabular}


damage mechanism is different between natural and accelerated corrosion. Comparatively, accelerated corrosion is uniform, and natural corrosion is uneven, especially with the development of corrosion.

The naturally carbonation-induced corrosion hot-rolled plain steel bar specimens were gained from a plant built in 1983 as shown in Fig. (1), which beared little load. The specimens could reflect real conditions, but the corresponding uncorroded specimens were impossible to be obtained. Therefore, six precise machining specimens were made from little corrosion steel bars. Three of them were static tension specimens as shown in Fig. (2), and the others were fatigue specimens as shown in Fig. (3). The material properties of the tension specimens were given in Table $\mathbf{3}$.

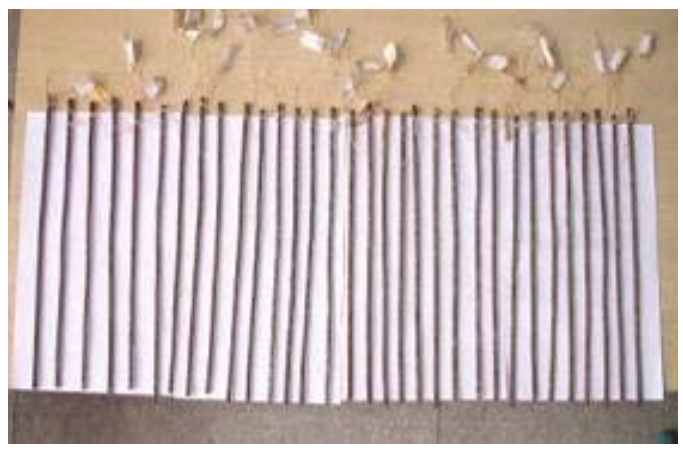

Fig. (1). Corrosion specimens.

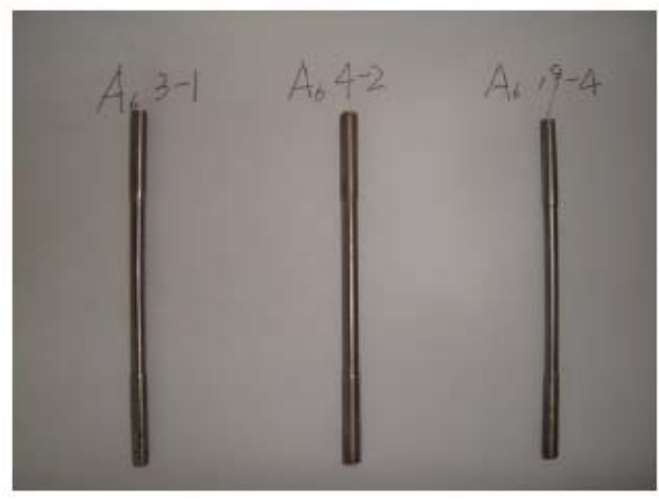

Fig. (2). Tension specimens.

Axial tensile fatigue tests of the specimens were conducted on the INSTRON 8502 fatigue machine under atmosphere environment according to standards [12, 13]. The constant amplitude loading was controlled by loads; the nominal stress level was from 0.5 to 0.6 ; the load ratio was settled 0.1 ; the loading form was sine wave; the loading frequency was from 5 to $10 \mathrm{~Hz}$; the specimen length was about $400 \mathrm{~mm}$.

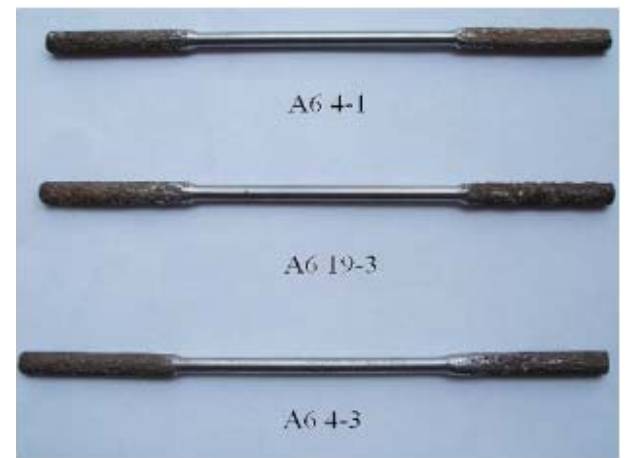

Fig. (3). Fatigue specimens.

The nominal stress level was maximum fatigue stress divided by ultimate strength of the tension specimens. The load ratio was minimum fatigue load divided by maximum fatigue load. Before testing, the loading mean value and amplitude value were calculated in the light of the nominal stress level, the cross section of the reinforcement after corrosion, the load ratio and the ultimate strength of control ones; then the loading form and frequency were selected; Finally, the fatigue machine started. The test finished when the specimen fractured. Attention, the datum was ineffectual if the specimen broke in the clamp position. Fig. (4) showed the fatigue test setup.

Few specimens broke at the clamp position as shown in Fig. (5). The fatigue fracture of corroded steel bar specimens was even without necking, and possessed distinct brittle fracture characteristic. Twelve natural corrosion specimens with a mass loss from 14.79 to $31.49 \%$ and three precise machining contrastive specimens were tested under constantamplitude fatigue loads. The maximum stresses of specimens were $260 \mathrm{MPa}, 230 \mathrm{MPa}$, and $200 \mathrm{MPa}$, and the corresponding nominal stress levels were $0.61,0.54$, and 0.47 . The paper mainly studied the deterioration of fatigue, but excepted the influence of cross section decrease. The fatigue test parameters and results of the fifteen specimens were given in Table 4.

For convenience, the mass loss of the specimens were approximately divided into zero, $15 \%, 20 \%, 25 \%$, and $30 \%$. The maximum stress and mass loss were selected to assess the fatigue performance of natural corrosion steel bars under constant amplitude load. The fatigue life relative values of specimens under specific mass loss and maximum stress were listed in Table 5. The fatigue life falls greatly with the increase of mass loss under the same stress, and the corrosion-induced attenuation ratio turns bigger with the stress increase.

With $S_{\max }=230 \mathrm{MPa}$ as an example, the fatigue life drops $70 \%, 77 \%, 79 \%$, and $87 \%$ respectively corresponding mass loss equal to $15 \%, 20 \%, 25 \%$, and $30 \%$. Obviously, the

Table 3. Steel Bar Properties

\begin{tabular}{|c|c|c|c|c|}
\hline Diameter $(\mathbf{m m})$ & Yield Strength $\boldsymbol{f}_{\mathbf{y}}(\mathbf{M P a})$ & Tensile Strength $\boldsymbol{f}_{\mathrm{u}}(\mathbf{M P a})$ & Elastic Modules $\boldsymbol{E}_{\mathrm{s}}(\mathbf{G P a})$ & Extension Rate $(\%)$ \\
\hline \hline 6.5 & 263 & 423 & 205 & 25 \\
\hline
\end{tabular}


fatigue life falls to more than $30 \%$ when the mass loss equal to $15 \%$. There is prominent stress concentration phenomenon for badly uneven corrosion along steel bars.

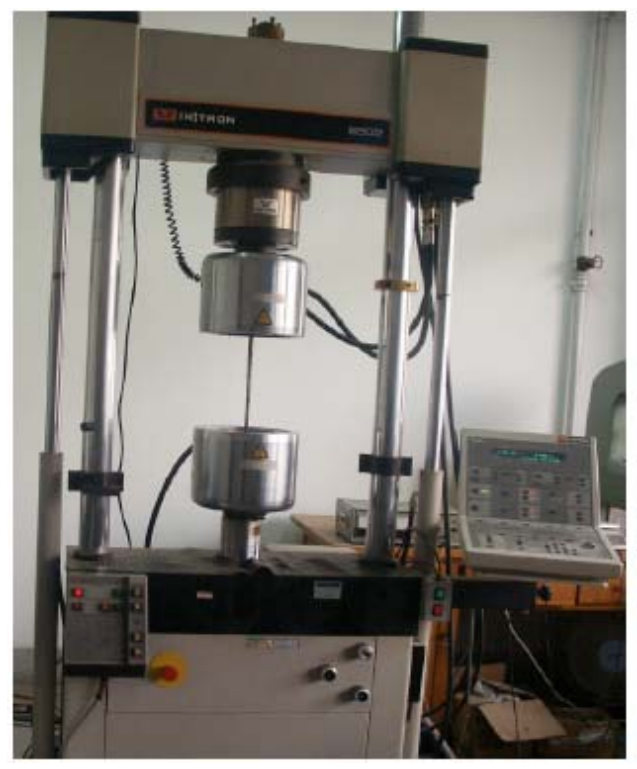

Fig. (4). Fatigue test setup.

With the development of corrosion, under the same alternate stress, the fatigue life of natural corrosion steel bars approximately decays according to negative power exponent law, and the attenuation rate increases with maximum stress increasing as shown in Fig. (6). In which, $F$ is the fatigue life relative value, and $x$ is the mass loss. All correlation coefficients are beyond 0.85 .

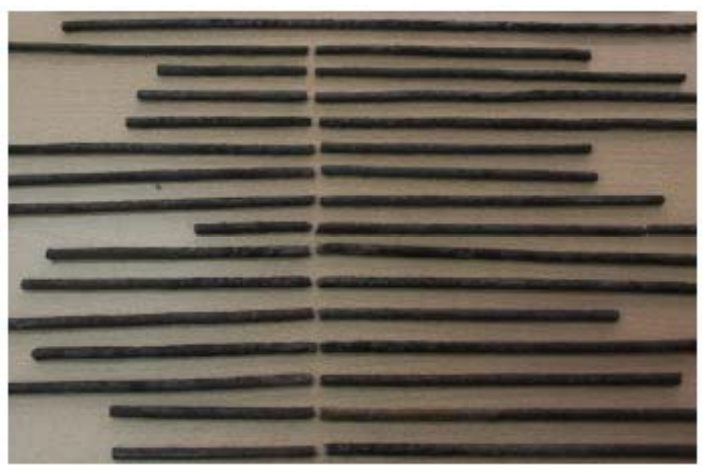

Fig. (5). Fatigue fracture pictures.

The deterioration form is similar to that of accelerated corrosion steel bars, but the deterioration velocity and rule are different from those of accelerated corrosion steel bars [8]. For accelerated corrosion specimens, the attenuation rate decreases with maximum stress increasing, and the value is equivalent to that of natural corrosion steel bars when the stress level is about 0.60 , but the value is 1.5 times higher than that of natural corrosion steel bars. Theoretically, under the same condition, the attenuation rate of natural corrosion bars is bigger than that of accelerated corrosion steel bars. The difference may be caused by corrosion conditions and reinforcement types. The accelerated corrosion specimens are chloride ion-induced hot-rolled crescent ribbed bars, but the natural corrosion specimens are carbonation-induced hot-

Table 4. Main Parameters and Results of Natural Corrosion Steel Barssteel Bar Properties

\begin{tabular}{|c|c|c|c|c|c|}
\hline Serial Number & Mass Loss(\%) & Stress Level & Maximum Stress(MPa) & Minimum Stress(MPa) & Fatigue Life $(N)$ \\
\hline$S_{\mathrm{I}} 1$ & 0 & 0.61 & 260 & 26 & 2703877 \\
\hline$S_{\mathrm{I}} 2$ & 15.62 & 0.61 & 260 & 26 & 652047 \\
\hline$S_{\mathrm{I}} 3$ & 20.30 & 0.61 & 260 & 26 & 378180 \\
\hline$S_{1} 4$ & 25.11 & 0.61 & 260 & 26 & 409344 \\
\hline$S_{1} 5$ & 29.26 & 0.61 & 260 & 26 & 192142 \\
\hline$S_{1} 6$ & 0 & 0.54 & 230 & 23 & 3631565 \\
\hline$S_{\mathrm{I}} 7$ & 14.79 & 0.54 & 230 & 23 & 1082585 \\
\hline$S_{\mathrm{I}} 8$ & 20.59 & 0.54 & 230 & 23 & 834025 \\
\hline$S_{\mathrm{I}} 9$ & 26.03 & 0.54 & 230 & 23 & 768166 \\
\hline$S_{\mathrm{I}} 10$ & 29.52 & 0.54 & 230 & 23 & 479190 \\
\hline$S_{\mathrm{I}} 11$ & 0 & 0.47 & 200 & 20 & 5244688 \\
\hline$S_{\mathrm{I}} 12$ & 15.10 & 0.47 & 200 & 20 & 1574442 \\
\hline$S_{\mathrm{I}} 13$ & 20.41 & 0.47 & 200 & 20 & 1881028 \\
\hline$S_{\mathrm{I}} 14$ & 25.20 & 0.47 & 200 & 20 & 1673075 \\
\hline$S_{\mathrm{I}} 15$ & 31.49 & 0.47 & 200 & 20 & 855960 \\
\hline
\end{tabular}


Table 5. Fatigue Life Relative Values of Specimens

\begin{tabular}{|c|c|c|c|}
\hline Maximum Stress(MPa) Mass Loss(\%) & $\mathbf{2 6 0}$ & $\mathbf{2 3 0}$ & $\mathbf{2 0 0}$ \\
\hline \hline 0 & 1.00 & 1.00 & 0.00 \\
\hline 15 & 0.24 & 0.30 & 0.30 \\
\hline 20 & 0.14 & 0.23 & 0.36 \\
\hline 25 & 0.15 & 0.13 & 0.16 \\
\hline 30 & 0.07 & 0.16 \\
\hline
\end{tabular}

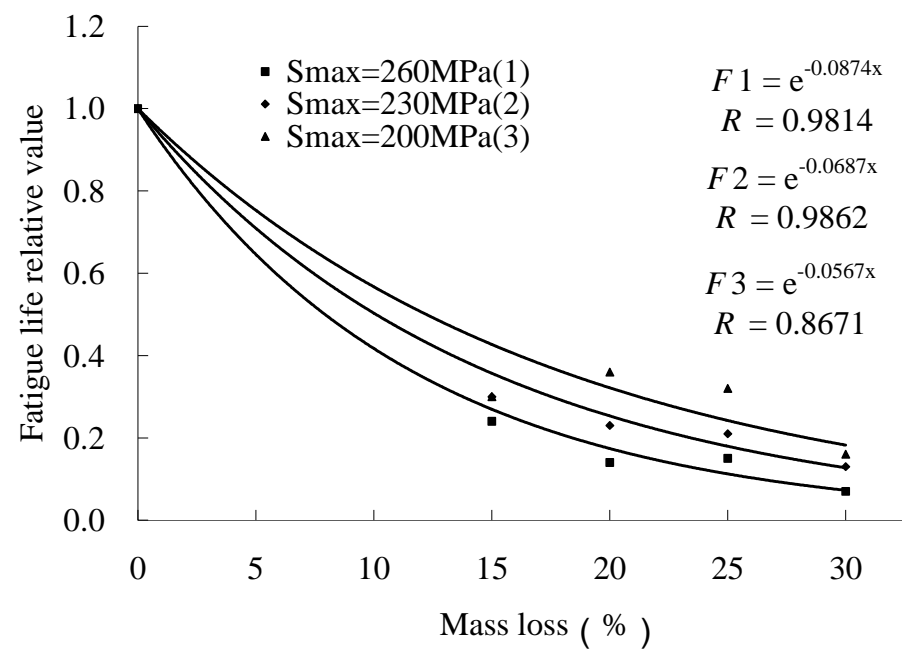

Fig. (6). Fatigue life decay law of specimens.

rolled plain bars. What's more, the mass loss of all natural corrosion specimens is nearly beyond $15 \%$.

\section{CONCLUDING REMARKS}

The production indicates that fatigue strength of the natural corrosion reinforcing steel bars is reduced significantly due to loading history and stress concentration phenomenon. In average, the fatigue strength of natural corrosion plane reinforcement with a mass loss of $4.60 \%$ drops $37.80 \%$.

The test results indicate that fatigue life of natural corrosion steel bars is reduced significantly due to stress concentration phenomenon caused by corrosion pits; fatigue life of natural corrosion steel bars decays according to negative power exponent law approximately, and the attenuation rate reduces with the decrease of stress level.

Fatigue of corrosion reinforcement is quite complex, which is affected by corrosion environment, loading conditions, steel bar type, steel bar diameter, and so on. Pertinent research has key significance. There is before us a heavy responsibility and a long way to go.

\section{ACKNOWLEDGEMENT}

This paper was supported by the National Natural Science Foundation of China (No.51008182), and the Key Project of Chinese Ministry of Education (No. 105070), and the Project of Chinese Ministry of Housing and Urban-Rural Development (No. 2008-K2-9).

\section{REFERENCES}

[1] C. Q. Li, and R.E. Melchers, "Time-dependent risk assessment of structural deterioration caused by reinforcement corrosion", ACI Structural Journal, vol. 102, no. 5, pp.754-764, 2005.

[2] W. Zhang, D. Shang, and X. Gu, "Stress-strain relationship of corroded steel bars", Journal of Tongji University (Natural Science), vol.34, no.5, pp. 586-592, 2006. (in Chinese)

[3] S. Li, "Flexural fatigue behavior and life prediction of corroded reinforced concrete beams", Doctor thesis, Tongji University, Shanghai, China, 2007. (in Chinese)

[4] J. Cao, and Y. Wen, "Fatigue experimental study on corrosion reinforcement", Journal of Changsha Railway University, vol. 16, no. 4, pp.15-18, 1998. (in Chinese)

[5] W. Zhang, S. Li, and X. Gu etc, "Experiment on axial tensile fatigue of naturally corroded steel bar", China Journal of Highroad and Transport, vol. 22, no. 2, pp.53-58, 2009. (in Chinese)

[6] Z. Zeng, and Z. Li, "Research on fatigue $S-N$ curves of reinforcing bars in common reinforced concrete beams", China Civil Engineering Journal, vol. 32, no. 5, pp.10-14, 1999. (in Chinese)

[7] Hongwei Tang, Shibin Li, and Donghai Xie etc, "Study on fatigue $S-N$ curves of corrosion-damaged reinforcement", Key Engineering Materials, vol. 324, pp.607-610, 2006.

[8] S. Li, W. Zhang, and X. Gu etc, "Fatigue of steel bar subjected to accelerated corrosion," in 13th International Conference and Exhibition on Structural Faults \& Repair, 2010, pp.78, Edinburgh, England.

[9] S. Li, W. Zhang, and X. Gu, "Experimental study on fatigue properties of corrosion-accelerated steel bars", Journal of the China Railway Society, vol. 32, no. 5, pp. 93-97, 2010. (in Chinese) 
[10] C.A. Apostolopoulos, and M.P. Papadopoulos, "Tensile and low cycle fatigue behavior of corroded reinforcing steel bars S400", Construction and Building Materials, no. 21, pp. 855-864, 2007.

[11] C. A. Apostolopoulos, "Mechanical behavior of corroded reinforcing steel bars S500s tempcore under low cycle fatigue", Construction and Building Materials, no. 21, pp.1447-1456, 2007.
[12] BS 4449-1988, "British standard specification for carbon steel bars for the reinforcement of concrete", 1988.

[13] GB 3075-82, "National standard of the People's Republic of China for the metal axial fatigue test method", 1982. (in Chinese)

Received: August 19, 2010

Revised: November 21, 2010

Accepted: December 03, 2010

(C) Li et al.; Licensee Bentham Open.

This is an open access article licensed under the terms of the Creative Commons Attribution Non-Commercial License

(http://creativecommons.org/licenses/_by-nc/3.0/) which permits unrestricted, non-commercial use, distribution and reproduction in any medium, provided the work is properly cited. 